\title{
Dual Glycation-Inflammation Modulation, DPP-IV and Pancraetic Lipase Inhibitory Potentials and Antiproliferative Activity of Novel Fluoroquinolones
}

\author{
Shereen Arabiyat ${ }^{1 *}$ Violet Kasabri $^{2}$, Yusuf Al-Hiari ${ }^{2}$, Ihab AL-MASRI ${ }^{3}$, Sundus \\ Alalawi $^{2}$, Yasser K Bustanji ${ }^{2,4}$
}

\begin{abstract}
Paramount efforts by pharmaceutical industry to identify new targets for obesity-diabetes (Diabesity) pharmacological intervention have led to a number of agents developed and directed at DPP IV [dipeptidyl peptidase IV] enzyme inhibition thereby enhancing endogenous insulinotropic incretins. Besides antioxidative-antiinflammtory molecules that inhibit accumulation of advanced glycation end products (AGEs) can be good candidates for ameliorating diabetic complications. Fluoroquinolones (FQs) have been identified recently as potent inhibitors of pancreatic lipase (PL). The suggested association between obesity and colorectal cancer initiated the evaluation of antiproliferative activity of the new FQs and TFQs against a panel of obesity related colorectal cells (HT29, HCT116, SW620 CACO2 and SW480). The aim of the current study is to examine the potential of newly synthesized FQs and triazolofluoroquinolones (TFQs) derivatives as dual inhibitors for glycation and inflammation, DPP IV inhibitors, PL inhibitors for dual management of obesity and diabetes, as well as antiprolifertaive efficacy against colorectal cancer cell lines. Sulforodamine B (SRB) colorimetric assay revealed that some derivatives exhibited unselective cytotoxity against HT29, HCT116, SW620 $\mathrm{CACO}_{2}$ and SW480. The superior antiglycation activity of the reduced derivatives $4 \mathrm{a}$ and $4 \mathrm{~b}$ over that of aminoguanidine with respective IC50 $(\mu \mathrm{M})$ values of $3.05 \pm 0.33$ and $8.51 \pm 3.21$; none of the tested synthetic compounds could perform equally effectively to Diprotin A, a dose dependent inhibitor of DPP IV. Compounds 4a, 5a, 3b, 4b and 5b demonstrated anti-inflammatory IC50 values exceeding that of indomethacin. Compounds $3 \mathrm{a}$ and $4 \mathrm{a}$ showed IC50 lower than $10 \mu \mathrm{M}$ as PL inhibitors. In conclusion, FQ and TFQ derivatives may unveil new antiobesity and anticancer agents in the future. Our research qualifies FQs and TFQs as promising candidates for the development of related $\alpha$-dicarbonyl scavengers as therapeutic agents to protect cells against carbonyl stress.
\end{abstract}

Keywords: Fluoroquinolones- glycation-inflammation- obesity- colorectal cancer- DPP IV-diabesity

Asian Pac J Cancer Prev, 20 (8), 2503-2514

\section{Introduction}

Fluoroquinolones (FQs) have been identified for over 40 years as one of the most clinically successful antibacterials (Appelbaum et al., 2000; Ball, 2000; Langer et al., 2003; Bolon 2011). FQs have other biological activities as antidiabetic (Edmont et al., 2000), antimycobacterial, pancreatic lipase inhibitors as well as anticancer properities (El-Rayes et al., 2002; Zhao et al., 2005; Shaharyar et al., 2007; Kathiravan et al., 2013; Al-Hiari et al., 2014). Triazole and its various derivatives possess a great importance in medicinal chemistry with wide range of biological activities including antioxidant, analgesic, antinflammatory, antianxiety, antimicrobials and anticancer properties (Asif, 2014; Asif, 2015; Haider et al., 2014). The hybrid structure triazoloquinolones (TQs) have been reported to exhibit antimicrobial, antiinfective of the urinary tract, antimycobacterial and antiAlzheimer activities (Carta et al., 2008). Nonenzymatic formation of advanced glycation end products (AGEs) takes place between reducing sugars and amino groups in proteins, lipids and nucleic acids. Recently, the accumulation of AGEs in vivo has been implicated as a major pathogenic process in atherosclerosis, Alzheimer's disease and normal aging (Peng et al., 2011). Also, accelerated AGEs accumulation under hyperglycemic conditions is characteristic to type 2 diabetes mellitus (DM) and contributes to the development of vascular complications (Harris et al., 2011). The interaction between AGE-modified proteins and AGE-specific 
receptors (RAGEs) on the cell surface induces the overproduction of reactive oxygen species (ROSs) and inflammatory mediators, which leads to cellular disorders in biological systems (Wu et al., 2011a; Wu et al., 2011b). Recently, more detrimental effects of AGEs in type 2 DM have emerged. AGEs interfere with the complex molecular pathway of insulin signalling, leading to insulin resistance; AGEs modify the insulin molecule, and, consequently, its function; AGEs decrease insulin secretion and insulin content (Coughlan et al., 2011; Puddu et al., 2011). Thus, Inhibition of RAGE was found to effectively protect $\beta$-cells against AGE-induced apoptosis (Zhu et al., 2011), but could not reverse islet dysfunction in glucose stimulated insulin secretion (GSIS; Shu et al., 2011). Additionally, AGEs suppression of insulin-stimulated glucose transport in adipocytes was blocked by anti-AGEs antibodies (Wu et al., 2011). The presence of glycated insulin has been demonstrated in plasma and pancreatic islets of diabetic patients (McKillop et al., 2000; Hunter et al., 2003). The sites of monoglycated and diglycated insulin entities were identified (O'Harte et al., 1996; O'Harte et al., 2000). A novel triglycated form of insulin was purified lately (Guedes et al., 2009). Glucotoxicity and non- enzymatic glycation were demonstrated to be controlled in vivo by deglycation systems including fructosamine-3-kinase (FN3K) mediated deglycation of fructosamines and transglycation of aldosamines. A transglycation product, glucose-cysteine, was found in human urine and its concentrations were increased in diabetes (Szwergold et al., 2005a; Szwergold, 2005b). It is hypothesized that cellular supplementation with very high concentrations of scavenging nucleophilic amino acids counteract non-enzymatic glycation and adverse effects of hyperglycemia (Szwergold, 2005). Glutathione, taurine, penicillamine (Keita et al., 1992; di Wu et al., 1999; Ramamurthy et al., 2003), dipeptides like carnosine and anserine, and alpha-thiolamines such as cysteine and cysteamine retard and reverse non- enzymatic glycation, acting as effective transglycation/deglycation agents (Argirova et al., 2003; Szwergold, 2005; 2006). As such, inhibition of AGE formation, especially the natural anti-AGE agents without adverse effects, represents a potential therapeutic target for the prevention of premature aging and treatment of diabetic complications (di Wu et al., 1999; Harris et al., 2011; Peng et al., 2011). Additionally, intense efforts by pharmaceutical industry to identify new targets for obesity-diabetes (Diabesity) pharmacological intervention has led to a number of agents developed and directed at DPP IV enzyme inhibition. DPP IV [dipeptidyl peptidase IV] is a serine aminopeptidase cleaving off dipeptides from the aminoterminus of peptides, with a preference for proline at the penultimate position (Vanhoof et al., 1992). Many of DPP IV substrates share a Xaa-Pro or Xaa-Ala motif at their amino-terminus. This sequence contributes to the biological activity of the peptides, and serves as a structural protection against non-specific proteolysis. DPP IV may therefore be a key modulator of the biological activity of several of these peptides (Vanhoof et al., 1992). Dipeptidyl peptidase-IV (DPP-IV) is involved in the inactivation of glucagon like peptide-1 (GLP-1), a potent insulinotropic peptide. Thus,
DPP IV inhibition can be an effective approach to treat type $2 \mathrm{DM}$ by potentiating insulin secretion (Gorrell et al., 2005; Hsu et al., 2013; Singh et al., 2017). Diprotin A is a selective reversible peptide inhibitor of DPP IV with in vivo antidiabetic effects (Jao et al., 2015; Zhang et al., 2015). DPP IV Inhibitors have the capacity to repair $\beta$-cell dysfunction and insulin resistance and show a safe CV profile in patients with type 2 DM (Gómez-Peralta et al., 2011; Horie et al., 2014; Kawalec et al., 2014; Savarese et al., 2016;). Thus new leads for DPP IV inhibition (Almasri et al., 2013) were scrutinized; among many were the FQs as in sparfloxacin (Saleh et al., 2012). FQs have also been proven as potential pancreatic lipase inhibitors (Al-Hiari et al., 2014). The capability of the quinolone family to target type II topoisomerases (gyrase and Topo IV) signifies its members as anticancer agents. Their ability to bind metal ions and ion cofactors represents an additional means of modulating their pharmacological responses (Sissi et al., 2003). The reported potential anticancer effect of FQs against human breast adenocarcinoma cell line (Shaharyar et al., 2007; Kathiravan et al., 2013) initiated FQs' anticancer testing against a panel of obesity related colorectal cancer cell lines (HT29, HCT116, SW620, $\mathrm{CACO} 2$ and SW480). This work involves synthesis of novel FQs and Triazolofluoroquinolones (TFQs) and evaluation of their in vitro DPP IV inhibition, dual glycation inflammation modulation, antiobesity and antiproliferative capabilities.

\section{Materials and Methods}

\section{Experimental \\ Materials}

Generally all of the chemicals and solvents used in this study were purchased as the analytical grade, unless indicated otherwise, and used directly without further purification. Cyclopropylamine (Acros, Belgium), p-butylaniline and p-ethylaniline (Sigma, St. Luis, MO, USA), stannous chloride (Fluka, Switzerland) were procured. Melting points ( $\mathrm{mp}$ ) were determined in open capillaries on a Stuart scientific electro-thermal melting point apparatus (Stuart, Staffordshire, UK) and are uncorrected. Thin layer chromatography (TLC) was performed on $10 \times 10 \mathrm{~cm}^{2}$ aluminum plates pre-coated with fluorescent silica gel GF254 (ALBET, Germany) and was visualized using UV lamp (at 254nm wave length/ short wave length/ long wavelength). Mobile phase mixtures were: 94:5:1 chloroform-methanolformic acid (CHCl3-MeOH-FA) (system 1) and 50:50 (n-hexane - ethyl actate) (system 2). Nuclear magnetic resonance spectra (NMR) were recorded on $400 \mathrm{MHz}$ Bruker Avance Ultrashield. The chemical shifts were reported in ppm relative to tetramethylsilane (TMS). Deuterated dimethylsulfoxide (DMSO d6) was used as the NMR solvents. Infrared (IR) spectra were recorded using Shimadzu 8400F FT-IR spectrophotometer Shimadzu, Kyoto, Japan). The samples were prepared as potassium bromide (KBr) (Merck, Darmstadt, Germany) disks. High- resolution mass spectra (HRMS) were measured in positive ion mode using electrospray ionization (ESI) technique by collision-induced dissociation on a Bruker 
APEX-4 (7 Tesla) instrument. The samples were dissolved in acetonitrile, diluted in spray solution (methanol/water $1: 1 \mathrm{v} / \mathrm{v}+0.1$ formic acid) and infused using a syringe pump with a flow rate of $2 \mu \mathrm{L} / \mathrm{min}$. External calibration was conducted using Arginine cluster in a mass range $\mathrm{m} / \mathrm{z} 175-871$.

Synthesis of novel title compounds; Scheme 1

Synthesis of ethyl 1-cyclopropyl-7-(4-ethyl-phenylamino)6-fluoro-8-nitro-4-oxo-1,4-dihydro-quinoline-3carboxylate (2a); Scheme 1

Three molar equivalents of p-ethylaniline $(4 \mathrm{~g}, 34 \mathrm{mmol})$ were added into a solution containing ethyl 7-chloro-1-cyclopropyl-6- fluoro-8- nitro-4-oxo1,4-dihydroquinoline-3-carboxylate (1, 4g, 11.3mmol) and $10 \mathrm{ml}$ of dimethylsulfoxide (DMSO) as a solvent and drops of pyridine and then was refluxed for $65-70^{\circ} \mathrm{C}$ under anhydrous conditions for (4-5) days. The reaction mixture monitored by TLC until no starting material remained then was left to crystallize at room temperature and the product was filtered and washed, left to dry in dark place to give yellowish red crystals. Colour of solid compound: yellowish red; yield $\approx 75 \%(3.5 \mathrm{~g}) ; \mathrm{mp}=179-180^{\circ} \mathrm{C} ; \mathrm{Rf}$ value in system $1=0.47$ and in system $2=0.25 .1 \mathrm{H} \mathrm{NMR}$ (400 Hz, DMSO d6): 0.9 (m, 4H, CH2-2', CH2-3'), 1.2(m, $5 \mathrm{H}, \mathrm{OCH} 2 \mathrm{CH} 3, \mathrm{CH} 2-2$ "'), 2.3 (m, 2H, CH2-1"'), 3.84 (m, 1H, NCH-1'), 4.22 (q, J = 7 Hz, 2H, OCH2CH3), 6.8 (d, J=8.2 Hz, 2H, H-2", H-6"), 7.22 (d, J=8.4 Hz, 2H, H-3", H-5"), 8.08 (d, 3JH-F= 12.7 Hz, 1H, H-5), 8.6 (br s, $1 \mathrm{H}, \mathrm{NH}), 8.96$ (s, 1H, H-2). 13C NMR (100 Hz, DMSO d6): 9.64 (2C, CH2-2', CH2-3'), 14.39 (CH3-2"'), 16.42 (OCH2CH3), 28.4 (CH2-2"'), 39.16 (NCH-1'), 56.35 $(\mathrm{OCH} 2), 107.2(\mathrm{C}-3), 112.7$ (d, 2JC-F $=22 \mathrm{~Hz}, \mathrm{C}-5), 121.7$ (2C, C-2", C-6"), 124.1 (C-4a), 126.2 (2C, C-3", C-5"), 130.5 (d, 2JC-F=11.8 Hz, C-7), 132.65 (C-8a), 136.7 (C-8), 137.36 (C-1"), 140.15 (C-4"), 151.76 (C-2), 152.4 (d, 1JC-F= 245 Hz, C-6), 166.87 (CO2Et), 175.41 (C-4). HRMS (ESI, +ve): calc. for $\mathrm{C} 23 \mathrm{H} 22 \mathrm{FN} 3 \mathrm{NaO} 5[\mathrm{M}+\mathrm{Na}]+$ (462.14414). Found 462.14405.IR (KBr): v 3366, 3060, 2355, 1725, 1612, 1518, 1460, 1311, 1088, 925cm-1. Anal. Calcd. For C23H22FN3O5 (439.15): C, 62.86; H, 5.05; N, 9.56 Found C, 62.44; H, 5.62; N, 9.94.

Synthesis of 1-cyclopropyl-7-(4-ethyl-phenylamino)-6fluoro-8-nitro-4-oxo-1,4-dihydro-quinoline-3-carboxylic acid (3a); Scheme 1

A vigorously stirred suspension of ethyl 1-cyclopropyl7-(4-ethyl-phenylamino)-6-fluoro-8-nitro-4-oxo-1,4dihydro-quinoline-3- carboxylate $(2 \mathrm{a}, 2 \mathrm{~g}, 4.6 \mathrm{mmol})$ in $12 \mathrm{~N} \mathrm{HCl}(28 \mathrm{~mL})$ and ethanol $(12 \mathrm{~mL})$ was heated at $80-85{ }^{\circ} \mathrm{C}$ under reflux conditions. Progress of the ester hydrolysis was monitored by TLC and was completed within 24-36h. Thereafter, the reaction mixture was cooled, poured onto crushed ice $(250 \mathrm{~g})$ and the resulting orange precipitate was collected, washed with cold water $(2 \times 20 \mathrm{~mL})$ and left to dry. Yield $\approx 1.6 \mathrm{~g}(86 \%)$. $\mathrm{mp}=$ $220-222{ }^{\circ} \mathrm{C}$; Rf value in system $1=0.33$ and in system $2=0.12$. 1H NMR (400 Hz, DMSO d6): 0.98-1.09 (2m, 4H, CH2-2', CH2-3', CH3-2"') ), 2.46 (m, 2H, CH2-1"'), 4.17 (m, 1H, NCH-1'), 6.93 (2H, H-2", H-6"), 7.04 (2H, H-3", H-5"), 8.08 (1H, H-5), 8.76 (br s, 1H, NH), 8.91 (s,
1H, H-2), 14.39 (br s, 1H, COOH). 13C NMR (100 Hz, DMSO d6): 9.62 (2C, CH2-2', CH2-3'), 15.24 (CH3-2"'), 27.11(CH2-1'”'), 39.89 (NCH-1'), 108.5 (C-3), 113.76 (d, 2JC-F= $22 \mathrm{~Hz}, \mathrm{C}-5), 119.06$ (2C, C-2”, C-6”), 119.69 (C-4a), 127.57 (2C, C-3", C-5"), 132.48 (C-8a), 133.35 (d, 2JC-F= $12 \mathrm{~Hz}, \mathrm{C}-7), 136.2$ (C-8), 138.46 (C-1"), 138.69 (C-4”), 151.53 (C-2), 151.75 (d, 1JC-F= 250 Hz, C-6), 164.38 (COOH), 174.85 (C-4). HRMS (ESI, +ve): calc. for $\mathrm{C} 21 \mathrm{H} 18 \mathrm{FN} 3 \mathrm{NaO} 5[\mathrm{M}+\mathrm{Na}]+(434.11282)$. Found 434.11302.IR (KBr): v 3,375, 3,044, 2,628, 2,355, 1,736, 1,621, 1,486, 1,308, 1,084, 924cm $\mathrm{cm}^{-1}$. Anal. Calcd. for C21H18FN3O5 (411.12): C, 61.31; H, 4.41; N, 10.21. Found C, 61.87; H, 4.61; N, 10.47

Synthesis of 8-amino-1-cyclopropyl-7-(4-ethylphenylamino)-6-fluoro-4-oxo-1,4-dihydro-quinoline-3carboxylic acid (4a); Scheme 1

A mixture of 1-cyclopropyl-7-(4-ethyl-phenylamino)6-fluoro-8-nitro-4-oxo-1,4-dihydro-quinoline-3carboxylic acid (3a, $1 \mathrm{~g}, 2.4 \mathrm{mmol})$ in $6.7 \mathrm{ml}$ of $12 \mathrm{~N} \mathrm{HCl}$, left stirring in ice bath $\left(0-5^{\circ} \mathrm{C}\right)$ for 15 minutes. After that, the ice bath was removed and $(1.8 \mathrm{~g}, 9.6 \mathrm{mmol})$ stannous chloride ( $\mathrm{SnCl} 2)$ was added portion wise and the reaction mixture left stirring overnight and monitored by TLC until completion. Then, the reaction mixture was poured on crushed ice to precipitate faint orange product that is collected by filtration and left to dry. Yield $\approx 0.65 \mathrm{~g}(71 \%)$. $\mathrm{mp}=275-277^{\circ} \mathrm{C}$ (decomposition); Rf value in system $1=$ 0.17 and in system $2=0.07$. $1 \mathrm{H} \mathrm{NMR}(400 \mathrm{~Hz}$, DMSO d6): 1.13-1.22 (m, 7H, CH2-2', CH2-3', CH3-2'”), 2.6 (m, 2H, CH2-1'"), 4.2 (m, 1H, NCH-1'), 4.53 (m, 2H, NH2, exchangeable), 6.62 (d, J= $8 \mathrm{~Hz}, 2 \mathrm{H}, \mathrm{H}-2$ ", H-6"), 7.01 (d, J=8 Hz, 2H, H-3", H-5"), 7.35 (d, J=12 Hz, 1H, H-5), 8.75 (s, 1H, H-2), 9.1 (br s, 1H, NH), 14.60 (br s, 1H, COOH).13C NMR (100 Hz, DMSO d6): 9.77 (2C, C-2', C-3'), 15.57 (CH3-2"'), 27.00 (CH2-1'”'), 38.52 (NCH-1'), 97.52 (d,2JC-F= 23Hz, C-5), 105.74 (C-3), 113.97 (2C, C-2", C-6”), 120.3 (d, 2JC-F=17 Hz, C-7), 124.15 (d, 3JC-F=10 Hz, C-4a), 126.86 (C-8), 127.71 (2C, C-3", C-5"), 133.79 (C-8a), 138.21 (d, 4JC-F= 4 $\mathrm{Hz}, \mathrm{C}-1$ "), 141.78 (C-4"), 150.2 (C-2), 156.08 (d, 1JC-F= $243 \mathrm{~Hz}, \mathrm{C}-6), 165.46(\mathrm{COOH}), 176.46$ (C-4). HRMS (ESI, +ve): calc. for $\mathrm{C} 21 \mathrm{H} 20 \mathrm{FN} 3 \mathrm{NaO} 5[\mathrm{M}+\mathrm{Na}]+(404.13864)$. Found 404.13822.IR (KBr): v 3420, 3341, 3066, 2491, 1672, 1581, 1486, 1436, 1325, 1322, 1087, 954cm-1. Anal. Calcd. for C21H20FN3O3 (381.15): C,66.13; H, 5.29; N, 11.02. Found: C, 66.81; H, 4.88; N, 11.46

Synthesis of 9-cyclopropyl-3-(4-ethyl-phenyl)-4-fluoro6-oxo-6,9-dihydro-3H-[1,2,3]triazolo[4,5-h]quinoline7-carboxylic acid (5a); Scheme 1

Compound 5a was synthesized through cyclization of preceding reduced acid $4 \mathrm{a}$. A mixture of 8-amino1-cyclopropyl-7-(4- ethyl-phenylamino)-6-fluoro-4oxo-1,4-dihydro-quinoline-3-carboxylic acid (4a, 0.5g, $1.3 \mathrm{mmol}$ ) and $20 \mathrm{~mL}$ aqueous $\mathrm{HCl}$ was left stirring in ice bath $\left(0-5^{\circ} \mathrm{C}\right)$ for 15 minutes. NaNO2 $(0.09 \mathrm{~g}, 1.3 \mathrm{mmol})$ dissolved in $10 \mathrm{~mL} \mathrm{H} 2 \mathrm{O}$ is then added drop wise. The reaction mixture was left stirring overnight. Progress of diazotization (cyclization) reaction was monitored by TLC and was completed within $24 \mathrm{hrs}$. Thereafter, the reaction 
mixture was cooled, poured onto crushed ice (250g) and the resulting off-white precipitate was collected, washed with cold water $(2 \times 20 \mathrm{~mL})$ and left to dry. Yield $\approx 0.25 \mathrm{~g}(49 \%) . \mathrm{mp}=298-300^{\circ} \mathrm{C}$; $\mathrm{Rf}$ value in system $1=$ 0.35 and Rf value in system $2=0.12$. $1 \mathrm{H} \mathrm{NMR}(400 \mathrm{~Hz}$, DMSO d6): 0.85 (m, 4H, CH2-2', CH2-3'), 1.23-1.47 (m, 7H, CH3- 2"”), 2.76 (m, 2H, CH2-1"”), 4.58 (m, 2H, NCH2-1'), 7.55 (2H, H-2", H-6"), 7.77 (2H, H-3", H-5"), 8.12 (br s, 1H, H-5), 8.84 (s, 1H, H-2), 13.8 (br s, 1H, COOH). 13C NMR (100 Hz, DMSO d6): 9.37 (2C, C-2', C-3'), 14.90 (CH3-2'"'), 28.22 (CH2-1'"'), 39.77 (CH2-1'), 108.77 (C-5), 109.57 (C-7), 122.6 (C5a), 125.9 (2C, C-2", C-6"), 127.3 (C-9b), 128.47 (2C, C-3", C-5”), 131.5 (C-9a), 132.45 (C-3a), 137.63 (C-4"), 144.61 (C-1"), 147.75 (d, 1JC-F=248.0 Hz, C-4), 148.42 (C-8), 164.91 (COOH), 175.59 (C-6). HRMS (ESI, +ve): calc. for $\mathrm{C} 21 \mathrm{H} 17 \mathrm{FN} 4 \mathrm{NaO} 3[\mathrm{M}+\mathrm{Na}]+(415.11824)$. Found 415.11865.IR (KBr): v 3435, 3066, 2671, 1726, $1635,1482,1132,1087,998 \mathrm{~cm}-1$. Anal. Calcd. for C21H17FN4O3 (392.13): C, 64.28; H, 4.37; N, 14.28. Found: C, 63.94; H, 4.72; N, 14.55

Synthesis of ethyl 7-(4-butyl-phenylamino)-1-cyclopropyl6-fluoro-8-nitro-4-oxo-1,4-dihydro-quinoline-3carboxylate (2b); Scheme 1

Three molar equivalents of p-butylaniline (3.1g, $21 \mathrm{mmol}$ ), were added into a solution containing ethyl 7-chloro-1-cyclopropyl-6- fluoro-8- nitro-4-oxo-1,4dihydroquinoline-3-carboxylate $(1,2.5 \mathrm{~g}, 7 \mathrm{mmol})$ and $10 \mathrm{~mL}$ of dimethylsulfoxide (DMSO) as a solvent and drops of pyridine. The mixture then was refluxed for $65-70^{\circ} \mathrm{C}$ under anhydrous conditions for 4-5 days. The reaction mixture was monitored by TLC until no starting material is left. The product was filtered and left to dry in dark place to give an orange precipitate; yield $\approx 78 \%$ (2.6g); mp: $245-248^{\circ} \mathrm{C}$ (Decomposition); Rf value in system $1=0.44$ and in system $2=0.28$. $1 \mathrm{H} \mathrm{NMR} \mathrm{(400}$ Hz, DMSO d6): 0.81 (t, 3H, CH3- 4"' ), 1.1-1.4 (m, 11H, CH2-2', CH2-3', OCH2CH3, CH2- 3"', CH2-2"'), 2.45 (m, 2H, CH2-1"'), 3.71 (m, 1H, NCH-1'), 4.22 (q, J = 7 $\mathrm{Hz}, 2 \mathrm{H}, \mathrm{OCH} 2 \mathrm{CH} 3$ ), 6.9 (d, J= 8 Hz, 2H, H-2", H-6"), 7.12 (d, J=8 Hz, 2H, H-3", H-5"), 8.15 (d, 3JH-F= 12 $\mathrm{Hz}, 1 \mathrm{H}, \mathrm{H}-5), 8.5$ (brs, 1H, NH), 8.9 (s, 1H, H-2). 13C NMR (100 Hz, DMSO d6): 9.88 (2C, CH2-2', CH2-3'), 14.39 (CH3-4"'), 15.65 (OCH2CH3), 21.54 (CH2-3"'), 33.4 (CH2-2",'), 34.2 (CH2-1",'), 39.19 (NCH-1'), $58.55(\mathrm{OCH} 2), 108.9(\mathrm{C}-3), 114.7$ (d, 2JC-F=21.75 Hz, C-5), 120.25 (2C, C-2", C-6"), 121.4 (d, 3JC-F=8.5 $\mathrm{Hz}, \mathrm{C}-4 \mathrm{a}), 127.6$ (2C, C-3", C-5"), 131.5 (d, 2JC-F= $12.8 \mathrm{~Hz}, \mathrm{C}-7), 134.4$ (C-8a), 136.7 (C-8), 136.4 (C-1"), 139.65 (C-4”), 152.89 (C-2), 152.8 (d, 1JC-F= $248 \mathrm{~Hz}$, C-6), 165.67 (CO2Et), 175.5 (C-4). HRMS (ESI, +ve): calc. for $\mathrm{C} 25 \mathrm{H} 26 \mathrm{FN} 3 \mathrm{NaO} 5[\mathrm{M}+\mathrm{Na}]+(490.17542)$. Found 490.17596. IR (KBr): v 3438, 3337, 2354, 1726, 1624, 1523, 1457, 1307, 1090cm-1. Anal. Calcd. for C25H26FN3O5 (467.19): C, 64.23; H, 5.61; N, 8.99 Found C, 64.64; H, 5.18; N, 9.22.

Synthesis of 7-(4-butyl-phenylamino)-1-cyclopropyl-6fluoro-8-nitro-4-oxo-1,4-dihydro-quinoline-3-carboxylic acid (3b); Scheme 1
A vigorously stirred suspension of ethyl 7-(4-butylphenylamino)-1-cyclopropyl-6-fluoro-8-nitro-4-oxo-1,4dihydro-quinoline-3- carboxylate $(2 \mathrm{~b}, 1.5 \mathrm{~g}, 3.2 \mathrm{mmol})$ in $12 \mathrm{~N} \mathrm{HCl}(28 \mathrm{~mL})$ and ethanol $(12 \mathrm{~mL})$ was heated at $80-85^{\circ} \mathrm{C}$ under reflux conditions. Progress of the ester hydrolysis was monitored by TLC and was completed within 24-36h. Thereafter, the reaction mixture was cooled, poured onto crushed ice (250 g) and the resulting yellow precipitate was collected, washed with cold water $(2 \times 20 \mathrm{~mL})$ and left to dry. Yield $\approx 78 \%(1.1 \mathrm{~g}) ; \mathrm{mp}=255$ $275^{\circ} \mathrm{C}$; Rf value in system $1=0.28$ and in system $2=0.20$. $1 \mathrm{H}$ NMR (400 Hz, DMSO d6): 0.84 (t, 3H, CH3- 4"'), 1.00 (m, 4H, CH2-2', CH2-3'), 1.23 (m, 2H, CH2- 3'"'), 1.47 (m, 2H, CH2-2"”), 2.48 (m, 2H, CH2-1"”), 1.48 (m, 2H, CH2-2"'), 3.71 (m, 1H, NCH-1'), 6.93 (d, J=8 Hz, 2H, H-2", H-6"), 7.04 (d, J= 8 Hz, 2H, H-3", H-5"), $8.12(\mathrm{~d}, 3 \mathrm{JH}-\mathrm{F}=12 \mathrm{~Hz}, 1 \mathrm{H}, \mathrm{H}-5), 8.78$ (br s, $1 \mathrm{H}, \mathrm{NH})$, 8.94 (s, 1H, H-2), 15.02 (br s, 1H, COOH). 13C NMR (100 Hz, DMSO d6): 9.67 (2C, CH2-2', CH2-3'), 16.39 (CH3-4"”), 21.31 (CH2-3"”), 32.82 (CH2-2"”), 23.9 (CH2-1"'), 39.29 (NCH-1'), 108.85 (C-3), 114.09 (d, 2JC-F= 20 Hz, C-5), 119.09 (2C, C-2", C-6”), 119.5 (d, $3 \mathrm{JC}-\mathrm{F}=9 \mathrm{~Hz}, \mathrm{C}-4 \mathrm{a}), 128.14$ (2C, C-3", C-5"), 132.5 (d, 2JC-F=14 Hz, C-7), 133.4 (C-8a), 133.5 (C-8), 137.09 (C-1"), 138.75 (C-4”), 151.89 (C-2), 152.0 (d,1JC-F= $240 \mathrm{~Hz}, \mathrm{C}-6), 164.42$ (COOH), 174.9 (C-4). HRMS (ESI, $+v e$ ): calc. for $\mathrm{C} 23 \mathrm{H} 22 \mathrm{FN} 3 \mathrm{NaO} 5[\mathrm{M}+\mathrm{Na}]+(462.14412)$. Found 462.14467. IR (KBr): v 4510, 3363, 1728, 1618, 1533, 1443, 1322, 1284, 1215, 996 cm-1. Anal. Calcd. for C23H22FN3O5 (439.15): C, 62.86; H, 5.05; N, 9.56. Found C, 63.22; H, 4.81; N, 10.33

Synthesis of 8-amino-7-(4-butyl-phenylamino)-1cyclopropyl-6-fluoro-4-oxo-1,4-dihydro-quinoline-3carboxylic acid (4b); Scheme 1

A mixture of 7-(4-butyl-phenylamino)-1-cyclopropyl6-fluoro-8-nitro-4-oxo-1,4-dihydro-quinoline-3carboxylic acid $(3 \mathrm{~b}, 0.6 \mathrm{~g}, 1.4 \mathrm{mmol})$ in $6.7 \mathrm{~mL}$ of $12 \mathrm{~N}$ $\mathrm{HCl}$ was left stirring in ice bath $\left(0-5^{\circ} \mathrm{C}\right)$ for 15 minutes. After that, the ice bath was removed and $(0.86 \mathrm{~g}, 4.5 \mathrm{mmol})$ stannous chloride ( $\mathrm{SnCl} 2)$ was added portion wise and the reaction mixture was left stirring overnight and monitored by TLC until completion. Then, the reaction mixture was poured on crushed ice to precipitate dark orange product that is collected by filtration and left to dry. Yield $\approx 63 \%$ $(0.38 \mathrm{~g}) ; \mathrm{mp}=176-180{ }^{\circ} \mathrm{C}$; Rf value in system $1=0.20$ and in system $2=0.09$. $1 \mathrm{H} \mathrm{NMR}(400 \mathrm{~Hz}$, DMSO d6): 0.78-0.98 (m, 4H, CH2-2', CH2-3'), 1.16 (m, 3H, CH24""), 1.21(m, 2H, CH2-3"'), 1.39 (m, 2H, CH2-2"”), 2.36 (m, 2H, CH2-1"”), 4.1 (m, 1H, NCH-1'), 4.17 (m, 2H, NH2, exchangeable), 6.5 (d, J=8 Hz, 2H, H-2", H-6"), 6.9 (d, J=8 Hz, 2H, H-3", H-5"), 7.22 (d, J=12 Hz, 1H, H-5), 8.56 (s, 1H, H-2), 8.7 (br s, 1H, NH), 14.60 (br s, 1H, COOH).13C NMR (100 Hz, DMSO d6): 10.83 (2C, C-2', C-3'), 14.15 (CH2- 4"'), 14.56 (CH2-3"'), 22.07 (CH2-2"'), 33.82 (CH2-1"”), 38.6 (CH-1'), 108.48 (d, $2 \mathrm{JC}-\mathrm{F}=23 \mathrm{~Hz}, \mathrm{C}-5), 107.2$ (C-3), 114.59 (2C, C-2”, C-6"), 121.45 (C-4a), 124.6 (C-8), 127.18 (d, 2JC-F= 17.4 Hz, C-7), 129.23 (2C, C-3", C-5"), 133.0 (C-8a), 137.15 (C-4"), 141.05 (C-1"), 151.9 (C-2), 156.54 (d, 1JC-F= $245 \mathrm{~Hz}, \mathrm{C}-6), 166.5(\mathrm{COOH}), 174.1(\mathrm{C}-4)$. 
HRMS (ESI, +ve): calc. for C23H24FN3NaO3 [M+ Na]+ (432.16994). Found 432.16915. IR (KBr): v 3087, 2916, 1725, 1631, 1516, 1467, 1375, $1003 \mathrm{~cm}-1$. Anal. Calcd. for $\mathrm{C} 23 \mathrm{H} 24 \mathrm{FN} 3 \mathrm{O} 3$ (409.18): C,67.47; H, 5.91; N, 10.26. Found: C, 67.94; H, 6.16; N, 9.88.

Synthesis of 3-(4-butyl-phenyl)-9-cyclopropyl-4-fluoro6-oxo-6,9-dihydro-3H-[1,2,3]triazolo[4,5-h]quinoline7-carboxylic acid (5b); Scheme 1

Compound $5 \mathrm{~b}$ was synthesized through cyclization of preceding reduced acid $4 \mathrm{~b}$. A mixture of 8-amino-7(4-butyl- phenylamino)-1-cyclopropyl-6-fluoro-4-oxo1,4-dihydro-quinoline-3-carboxylic acid (4b, $0.3 \mathrm{~g}, 0.7$ $\mathrm{mmol}$ ) and $20 \mathrm{~mL}$ aqueous $\mathrm{HCl}$ was left stirring in ice bath $\left(0-5^{\circ} \mathrm{C}\right)$ for 15 minutes. NaNO2 $(0.05 \mathrm{~g}, 0.7 \mathrm{mmol})$ dissolved in $10 \mathrm{~mL} \mathrm{H} 2 \mathrm{O}$ is added drop wise and the reaction mixture was left stirring overnight. Progress of diazotization (cyclization) reaction was monitored by TLC and was completed within 24 hrs. Thereafter, the reaction mixture was cooled, poured onto crushed ice (250 g) and the resulting off-white precipitate was collected, washed with cold water $(2 \times 20 \mathrm{~mL})$ and left to dry. Yield $\approx 70 \%(0.21 \mathrm{~g}) . \mathrm{mp}=315-318^{\circ} \mathrm{C}$; Rf value in system $1=$ 0.33 and $\mathrm{Rf}$ value in system $2=0.22$. $1 \mathrm{H} \mathrm{NMR}(400 \mathrm{~Hz}$, DMSO d6): 0.9 (m, 4H, CH2-2', CH2-3'), 1.27-1.85 (m, 7H, CH2-4", CH2-3"', CH2- 2" "), 2.74 (m, 2H, CH21 "'), 4.59 (m, 2H, NCH2-1'), 7.52 (2H, H-2", H-6"), 7.76 (2H, H-3", H-5"), 8.17 (br s, 1H, H-5), 8.91 (s, 1H, $\mathrm{H}-2), 14.6$ (br s, 1H,COOH).13C NMR (100 Hz, DMSO d6): 9.41 (2C, C-2', C-3'), 13.28 (CH2-4'”'), 21.29 (CH23"'), 32.64 (CH2-2'”), 34.45 (CH2-1"'), 41.5 (CH2-1'), 109.35 (C-5), 110.27 (C-7), 122.6 (C-5a), 124.96 (2C, C-2", C-6”), 127.23 (C-9b), 129.17 (2C, C-3", C-5”), 130.52 (C-9a), 133.5 (C-3a), 136.65 (C-4"), 144.84 (C-1"), 147.17 (d, 1JC-F= 250.0 Hz, C-4), 147.66 (C-8), $165.95(\mathrm{COOH}), 176.6$ (C-6). HRMS (ESI, +ve): calc. for $\mathrm{C} 23 \mathrm{H} 21 \mathrm{FN} 4 \mathrm{NaO} 3[\mathrm{M}+\mathrm{Na}]+(443.14954)$. Found 443.14988. IR (KBr): v 3064, 2982, 1726, 1615, 1478, $1187,1093,1003 \mathrm{~cm}-1$. Anal. Calcd. for C23H21FN4O3 (420.16): C, 65.70; H, 5.03; N, 13.33. Found: C, 65.14; H, $5.43 ; \mathrm{N}, 13.79$

\section{Antiglycation determination in vitro via Metheylglyoxal induced cytotoxicity}

A continuous cell line of murine macrophages cells (RAW 264.7) were routinely cultured in DMEM enriched with the following supplements (mentioned with their corresponding final concentrations): Fetal Bovine Serum (FBS) $(10 \%)$, streptomycin sulfate $(100 \mathrm{mg} / \mathrm{ml})$, pencillin $(100 \mathrm{U} / \mathrm{ml})$, gentamicin $(50 \mu \mathrm{g} / \mathrm{ml})$, beta-mercaptoethanol $(50 \mu \mathrm{M})$, HEPES buffer $(10 \mathrm{mM})$, L-glutamine (2 mM). The cells were cultured routinely and harvested biweekly using 1\% trypsin-EDTA. The cells were seeded at 104 cell/ well in 96-well tissue culture plates and incubated at $37^{\circ} \mathrm{C}$ and $5 \% \mathrm{CO} 2$ overnight. After $12 \mathrm{hr}$ incubation, the cells were treated with the test compound (in DMSO such that the maximum final concentration of each on cells did not exceed $1 \%$ ) in $10-50 \mu \mathrm{g} / \mathrm{mL}$ concentrations 20 minutes prior to the glycating sugar methylglyoxal "MGO" $(300 \mu \mathrm{M})$ treatment. $\mathrm{IC}_{50}$ value of MGO induced cytoxicity in RAW264.7 macrophages was determined over 4 concentrations $(100-400 \mu \mathrm{M})$. To rule out the possible interfering effects, the following controls were used: 1) Negative control: Normal cells: cells in culture medium only without test compound or MGO were used as a control for the natural growth/death of cells. 2) Positive control: cells with AMG at $1 \mathrm{mM}$ and MGO (Wondrak et al., 2002) 3) Test compound control: the cells with the test compound only (with no MGO) were incubated in their respective test concentration gradients to assess the effect of the test compound on the cells, 4) Co-solvent control: each co-solvent was added in its maximum concentration over non-treated cells to assess its effect on cells. The cells were then incubated for $48 \mathrm{hr}$ and assessed for viability using Sulforhodamine B (SRB; Santa Cruz Biotechnology, Inc. Texas, USA) colorimetric assay for cytotoxicity screening and mechanism of reduction of cell viability as described previously (Vichai and Kirtikara, 2006). The absorbance was read at $570 \mathrm{~nm}$ and $630 \mathrm{~nm}$ as a reference wavelength using absorbance plate reader (Biotek, ELx800). The activity of the test compound was assessed by calculating the percentage of viable treated cells versus negative control. Cell viability of $\leq 70 \%$ was considered as toxicity cut-off point (Farsalinos et al., 2013).

\section{Anti-Inflammatory (Nitrite) Determination in Vitro}

Murine macrophage cell line RAW 264.7 were cultured in high glucose DMEM supplemented with $10 \%$ foetal bovine serum (FBS), penicillin $(100 \mathrm{U} / \mathrm{mL})$, streptomycin $(100 \mu \mathrm{g} / \mathrm{mL})$, and L-glutamate $(100 \mu \mathrm{g} / \mathrm{mL})$ in a 37 oC humidified atmosphere with $95 \%$ air and 5\% $\mathrm{CO} 2$. The cells $\left(2 \times 10^{5} /\right.$ well $)$ were incubated with test compounds (3a-5a and 3b-5b) at different concentrations $(5-200 \mu \mathrm{g} / \mathrm{mL})$ in the presence of lipopolysaccharide (10 $\mu \mathrm{g} / \mathrm{mL}$; Sigma, St. Luis, MO, USA) for $24 \mathrm{~h}$. Following overnight incubation, aliquots of $100 \mu \mathrm{L}$ of cell culture media were mixed with $100 \mu \mathrm{L}$ Greiss reagent $(50 \mu \mathrm{L}$ of $1 \%$ Sulfamilamide in $5 \%$ phosphoric acid and $50 \mu \mathrm{L}$ of $0.1 \%$ napthylehtyllenediamine-HCL), and incubated at RT for $10 \mathrm{~min}$. Absorbance at $550 \mathrm{~nm}$ was determined using microplate reader (Bio- Tek Instrument, USA). The concentration of nitrite was determined by comparison with sodium nitrite standard curve. SRB cytotoxity protocol was performed for evaluation of the effect of test compounds (3a-5a and 3b-5b) on RAW 264.7 viability (Ghimeray et al., 2015; Assanga et al., 2017) Indomethacin (25-200 $\mu \mathrm{g} / \mathrm{mL}$ ) served as the positive control (Huang et al., 2016).

\section{Measurement of DPP IV inhibition in vitro}

All chemicals of analytical grade (DPPIV from porcine kidney, Gly-pro-p-nitroanilide, Diprotin-A (Ile-Pro-Ile), and Tris-HCl Buffer were purchased from Sigma, St Louis, USA. Test compounds were dissolved in DMSO and diluted with the assay buffer (Tris, $\mathrm{pH}$ 7.5). The DMSO concentration was less than $1.0 \%$ in all experiments and controls. In a 96-well titer plate reader, inhibition assay was conducted in triplicates. The assay was based on the cleavage of the chromogenic substrate Gly-propara-nitroanilide (GPPN) by the serine protease DPP-IV resulting in release of Paranitroaniline (pNA), a yellow 
colored product measured at $405 \mathrm{~nm}$ (Bio-TEK, USA) (Chakrabarti et al., 2011). Diprotin A or test compounds $(0.01-100 \mu \mathrm{g} / \mathrm{mL})$ were in the final volume of $35 \mu \mathrm{L}$ in Tris-HCl Buffer (50mM, pH 7.5). DPP-IV enzyme (0.05U/ $\mathrm{ml} ; 15 \mu \mathrm{L}$ ) was added and the mixture was pre-incubated for 10 minutes at $37^{\circ} \mathrm{C}$. One unit enzyme activity was defined as the amount of enzyme that catalyzes the release of $1 \mu \mathrm{mol} \mathrm{pNA}$ from the substrate/min under assay conditions. GPPN $(50 \mu \mathrm{L}$ of $0.2 \mathrm{mM}$ in Tris- $\mathrm{HCl})$ was added for 30 minutes incubation at $37^{\circ} \mathrm{C}$. The reaction was terminated by addition of $25 \mu \mathrm{L}$ of $25 \%$ glacial acetic acid. All values are represented as Mean \pm Standard Deviation. The $\%$ inhibition $=100-(($ Absorbance of inhibitor/ Absorbance of control) /Absorbance of control $\mathrm{x} 100)$. The $\mathrm{IC}_{50}$ value represents the amount of inhibitor required to achieve $50 \%$ enzyme inhibition.

Preparation of the test compounds and orlistat for the in vitro PL activity assay and quantification of PL activity by spectrophotometric assay

Orlistat (the golden antilipolytic standard; $10 \mathrm{mg}$, Sigma, St. Luis, MO, USA) was dissolved in DMSO (10 $\mathrm{mL})$ to give a stock solution $(1 \mathrm{mg} / \mathrm{mL})$, which was used to make six different working solutions with concentrations in the range of $0.625-20 \mu \mathrm{g} / \mathrm{mL}$. Thereafter, $20 \mu \mathrm{L}$ aliquots of each working solution were used in the reaction mixture to give final concentrations in the range of $0.0125-0.4 \mu \mathrm{g} / \mathrm{mL}$. Furthermore the test compounds were initially dissolved in DMSO to give three stock solutions, which were subsequently diluted to give five different stock solutions $(0.01-100 \mathrm{mg} / \mathrm{mL})$. Thereafter, $20 \mu \mathrm{L}$ aliquots of each stock solution were used in the reaction mixture to give the final concentration range $(0.2$ $-2000 \mu \mathrm{g} / \mathrm{mL})$. Crude porcine PL type II $(0.5 \mathrm{mg} / \mathrm{mL})$ (Sigma, St. Luis, MO, USA, EC 3.1.1.3) was suspended in Tris- $\mathrm{HCl}$ buffer (2.5 mM, pH 7.4, Promega Corp. WI, USA) to a final concentration of 200 units $/ \mathrm{mL}$. A $100 \mu \mathrm{M}$ solution of para-nitrophenyl butyrate (p-NPB, Sigma, St. Luis, MO, USA) in DMSO was used as the PL substrate. Aliquots $(0.1 \mathrm{~mL})$ of the PL solution were added to the reaction mixtures and the volumes were made up to 1 $\mathrm{mL}$ with Tris- $\mathrm{HCl}$ buffer. The PL was preincubated with different concentrations of the test material for at least 1 min prior to the addition of the substrate. The reactions were maintained at $37^{\circ} \mathrm{C}$ and initiated by the addition of $5 \mu \mathrm{L}$ of the $\mathrm{p}$-NPB substrate solution. The $\mathrm{p}$ - nitrophenol released during the reaction was measured at $410 \mathrm{~nm}$ using a SpectroScan 80D UV-VIS spectrophotometer (Sedico Ltd., Nicosia, Cyprus) over a minimum of five time points (1-5 min), against a blank of the same mixture containing the denatured enzyme. The catalytic activity of PL was determined colorimetrically by measuring its activity towards the hydrolysis of p-NPB to p-nitrophenol. The activity of PL in this reaction was quantified by measuring the increase in the rate of the release of p-nitrophenol from the slope of the linear segment of the absorbance versus time profiles (Arabiyat et al., 2016). The percentage of residual PL activity was determined for all of the test compounds relative to the control compounds, to calculate the concentration required to inhibit the activity of PL by $50 \%$ (i.e., the $\mathrm{IC}_{50}$ ). All of the assays were performed in triplicate and the calculated activities reported as the mean values \pm SD $(n=3)$. The PL inhibition values (\%) were calculated according to the following formula: Inhibition $(\%)=100-[(\mathrm{B} / \mathrm{A}) \times 100]$, where $\mathrm{A}$ is the PL activity in the absence of an inhibitor or test compound and $\mathrm{B}$ is the PL activity in the presence of an inhibitor or test compound.

\section{In vitro antiproliferative assay}

Obesity related colorectal cell lines HT29, HCT116, SW620 and SW480 were generously provided by Dr Rick F. Thorne (University of Newcastle, Australia) and were cultured in high glucose DMEM containing 10\% FCS (Bio Whittaker, Verviers, Belgium). CACO2 cell line was cultured in RPMI 1640 containing 10\% FBS, HEPES Buffer (10 mM), L-glutamine ( $2 \mathrm{mM})$, gentamicin $(50 \mu \mathrm{g} / \mathrm{mL})$, penicillin $(100 \mathrm{U} / \mathrm{mL})$, and streptomycin sulfate $(100 \mathrm{mg} / \mathrm{mL})$ (Sigma, St. Luis, MO, USA). The cytotoxicity measurements were determined using Sulforhodamine B (SRB; Santa Cruz Biotechnology, Inc. Texas, USA) colorimetric assay for cytotoxicity screening and mechanism of reduction of cell viability as described previously (Vichai and Kirtikara, 2006). Human periodontal fibroblasts (PDL) are a primary cell culture for verification of selective cytotoxicity with the least antiproliferative $\mathrm{IC}_{50}$ value obtained. As a robust and classical antineoplastic reference agent, cisplatin (1-100 $\mu \mathrm{g} / \mathrm{mL}$, Sigma, St. Luis, MO, USA) was recruited for comparison purposes (Kasabri et al., 2014). All of the assays were performed in triplicate and the calculated antiproliferative activities were reported as the mean values $\pm \mathrm{SD}(\mathrm{n}=3)$.

\section{Docking experiment}

The chemical structure of FQ derivatives (scheme 1) were sketched in MarvinSketch (58) and saved in molfile format. Subsequently, an ensemble of low energy conformers was generated using OMEGA software (59). OMEGA rapidly generates conformational ensembles of small molecules using a fragment-based library to build initial models of structures by bring together these fragment templates followed by rule-based torsion search stage. The generated conformers, saved in SDF format, were then docked into the binding site of pancreatic lipase (PDB code: 1LPB, resolution; $2.46 \AA$ ) (60) using FRED within the OEDocking suite (61). FRED docks pre-generated multiconformer molecules within a box enclosing the active site of a single receptor using an exhaustive search that systematically searches rotations and translations of each conformer of the molecule within the active site. Following the exhaustive search the top scoring poses are optimized and assigned a final score using Chemgauss4 (2015).

\section{Results}

\section{Synthesis of novel compounds}

Synthesis of compounds 1 was carried out following a previously reported procedure (Al-Hiari et al., 2007). Compounds $2 \mathrm{a}$ and $2 \mathrm{~b}$ were synthesized by the reaction of p-ethylaniline and p-butylaniline with 1, respectively; scheme 1 . Hydrolysis of nitro esters $2 \mathrm{a}$ and $2 \mathrm{~b}$ has 
generated the respective nitro acids $3 \mathrm{a}$ and $3 \mathrm{~b}$ in high yield. The 8-nitro derivatives $3 \mathrm{a}$ and $3 \mathrm{~b}$ were reduced to their respective amines $4 \mathrm{a}$ and $4 \mathrm{~b}$ with stannous chloride in aqueous $\mathrm{HCl}$. Compounds $4 \mathrm{a}$ and $4 \mathrm{~b}$ were cyclized to their respective TFQs $5 \mathrm{a}$ and $5 \mathrm{~b}$ using $\mathrm{NaNO} 2$ in aqueous $\mathrm{HCl}$ via diazotization reaction, scheme 1 . Compounds $3 a-5 a$ and $3 b-5 b$ were identified and characterized by IR, MS, EA and $1 \mathrm{H}$ and 13C NMR spectroscopic analyses. Their data is presented in the experimental part.

\section{Anti-glycation effects on methylglyoxal induced cytotoxicity}

In this newly developed screening method adapted to 96-well microtiter plate, the identification of carbonyl scavengers was based to using a rapid glycation system that proceeds independent of oxygen, and therefore, excludes identification of inhibitory compounds acting as antioxidants. MGO exerted a cytotoxicity $\mathrm{IC}_{50}$ value of $306.15 \pm 45.6 \mu \mathrm{M}$; henceforth it was the choice glucotoxicity concentration. Aminoguanidine (AG) was identified as a potent inhibitor of non-oxidative advanced glycation with an $\mathrm{IC}_{50}$ value of $3.1 \pm 0.35 \mu \mathrm{M}$ (its unselective cytotoxicity $\mathrm{IC}_{50}$ value $(5394.4 \pm 1345.21 \mu \mathrm{M})$ in absence of MGO was more than a 1000 fold increment of its efficacious antiglycation range). Comparative analyses demonstrated the superior antiglycation activity of the reduced derivatives $4 \mathrm{a}$ and $4 \mathrm{~b}$ over that of $A G$ with respective $\mathrm{IC}_{50}(\mu \mathrm{M})$ values of $3.05 \pm 0.33$ and $8.51 \pm 3.21$; thus hugely exceeding their respective efficacy ranges (Table 1). Compound $3 \mathrm{~b}$ could impressively exert a moderate protection against methylglyoxal-induced carbonyl toxicity $\left(\mathrm{IC}_{50}\right.$ value of $\left.85.12 \pm 7.07 \mu \mathrm{M}\right)$ with a highest safety profile among the rest, AG inclusive. Our research qualifies FQs and TFQs as promising candidates for the development of related $\alpha$-dicarbonyl scavengers as therapeutic agents to protect cells against carbonyl stress.

\section{Anti-inflammatory effects on LPS-stimulated RAW 264.7 mouse macrophages}

The inhibitory bioactivities of compounds $3 a-5 a$ and 3b-5b against LPS-induced nitric oxide (NO) production in RAW 264.7 macrophages were examined using the Griess assay. Incomparably exceeding the positive control drug indomethacin $\left(\mathrm{IC}_{50}\right.$ value $\left.=212 \mu \mathrm{M}\right)$ efficacy; the descending order of compounds with remarkable anti-inflammatory activities was: $3 b>4 b>5 a>4 a>5 b$. A moderate antiinflammatory activity was exhibited by 3a. Unlike the rest; 3 b exerted cytotoxicity against RAW 264.7 macrophages with an $\mathrm{IC}_{50}$ value of $326.7 \pm 53.5$ $\mu \mathrm{M}$; exceptionally it was 14 -folds its anti-inflammatory $\mathrm{IC}_{50}$ value of $23.8 \pm 2.4 \mu \mathrm{M}$, hugely exceeding its efficacy range (Table 1).

\section{In vitro DPP IV inhibition}

Diprotin A is a selective reversible peptide inhibitor of DPP IV with in vivo antidiabetic effects (Jao et al., 2015; Zhang et al., 2015). DPP IV is involved in the inactivation of GLP-1, a potent insulinotropic peptide. Thus, DPP IV inhibition can be an effective approach to treat type $2 \mathrm{DM}$ by potentiating insulin secretion (Hsu et al., 2013; Singh et al., 2017). Nevertheless and highly unlike Diprotin A dose dependent inhibition of DPP IV with an $\mathrm{IC}_{50}$ value of $5.14 \pm 0.75 \mu \mathrm{M}$, none of the tested synthetic compounds could perform equally effectively (Table 1).

FQs' and TFQ' as In vitro inhibitors of PL activity and modulators of obesity related colorectal cancer cell lines proliferation

Substantially based to the antilipolytic activity of newly synthesized antimicrobial agents (Al-Hiari et al., 2014); this study aims is to examine new potential PL inhibitors for dual management of obesity and diabetes. The $\mathrm{IC}_{50}$ value of the standard compound orlistat was $0.2 \mu \mathrm{M}$, which was comparable to the values cited in the literature (Bently et al., 2012; Habtemariam, 2012). Currently the tested compounds were recognized for their dose-dependent anti-PL activity with their $\mathrm{IC}_{50}$ values displayed in Table 2. The descending order of antilipase activity was: the nitro derivatives ( $3 a$ and $3 b$ ) $>$ the reduced derivatives $(4 \mathrm{a}$ and $4 \mathrm{~b})>$ TFQs $(5 \mathrm{a}$ and

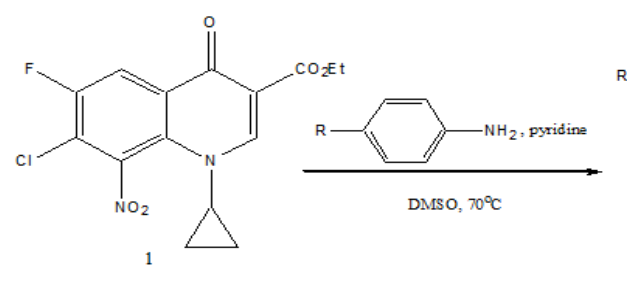<smiles>CCOC(=O)c1cn(C2CC2)c2c([N+](=O)[O-])c(Nc3ccc(F)cc3)c(F)cc2c1=O</smiles>

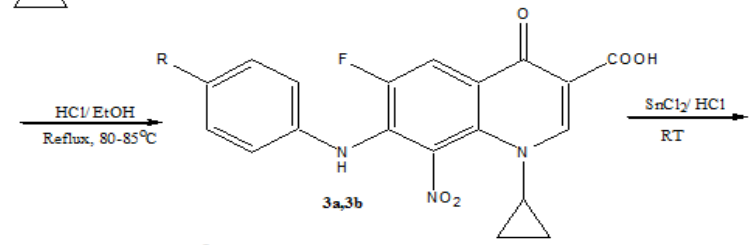
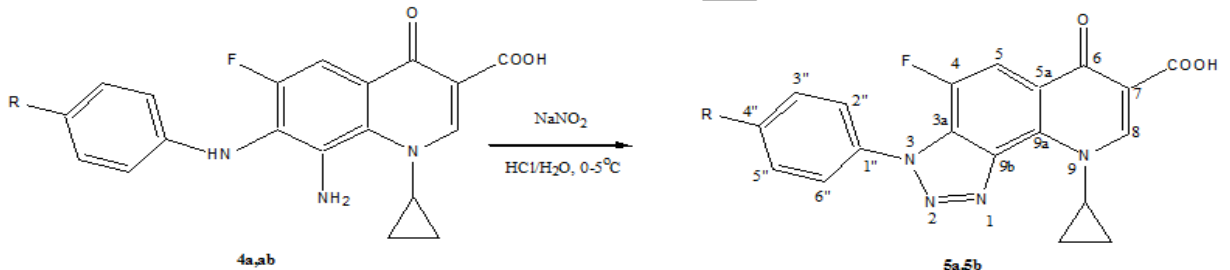

Scheme 1. Synthesis of Target Compounds (a, R= ethyl; b, R= butyl) 
Table $1 . \mathrm{IC}_{50}$ Values $(\mu \mathrm{g} / \mathrm{mL} ; \mu \mathrm{M})$ of In vitro Antiinflammatory Activities of Tested Compounds and Reference Drugs on LPS-Induced Nitric Oxide Production and Methylglyoxal Induced Cytotoxicity in RAW264.7 Murine Macrophages

\begin{tabular}{|c|c|c|c|c|c|}
\hline Treatment & $\begin{array}{c}{\text { Glycation- } \mathrm{IC}_{50}} \\
\text { value } \\
\mu \mathrm{M}(\mu \mathrm{g} / \mathrm{mL})\end{array}$ & $\begin{array}{c}\text { Glycation related Cytotox.- } \\
\mathrm{IC}_{50} \text { value } \\
\mu \mathrm{M}(\mu \mathrm{g} / \mathrm{mL})\end{array}$ & $\begin{array}{c}\text { NOS-IC }_{50} \text { value } \\
\mu \mathrm{M}(\mu \mathrm{g} / \mathrm{mL})\end{array}$ & $\begin{array}{c}\text { NOS related } \\
\text { Cytotox.- } \mathrm{IC}_{50} \text { value }\end{array}$ & $\begin{array}{c}\text { DPP4-IC } \text { I0 }_{50} \text { value } \\
\mu \mathrm{M}(\mu \mathrm{g} / \mathrm{mL})\end{array}$ \\
\hline \multirow[t]{2}{*}{$3 a$} & $463.7 \pm 89.9$ & $436.8 \pm 67$ & $309.1 \pm 46.4$ & NI & NI \\
\hline & $(190.7 \pm 37)$ & $(179.7 \pm 27.6)$ & $(127.17 \pm 20.34)$ & & \\
\hline \multirow[t]{2}{*}{$4 a$} & $0.071 \pm 0.011$ & $3.05 \pm 0.33$ & $60.0 \pm 1.1$ & NI & NI \\
\hline & $(0.027 \pm 0.004)$ & $(1.2 \pm 0.13)$ & $(22.9 \pm 0.44)$ & & \\
\hline \multirow[t]{2}{*}{$5 \mathrm{a}$} & $64.79 \pm 7.56$ & $84.09 \pm 2.31$ & $51.5 \pm 7.3$ & NI & NI \\
\hline & $(25.4 \pm 2.97)$ & $(33.0 \pm 0.90)$ & $(20.2 \pm 2.9)$ & & \\
\hline \multirow[t]{2}{*}{$3 b$} & $85.12 \pm 7.07$ & NI & $23.8 \pm 2.4$ & $326.7 \pm 53.5$ & NI \\
\hline & $(37.4 \pm 3.11)$ & & $(10.5 \pm 1.06)$ & $(143.6 \pm 23.5)$ & \\
\hline \multirow[t]{2}{*}{$4 b$} & $0.54 \pm 0.07$ & $8.51 \pm 3.21$ & $29.8 \pm 3.6$ & NI & NI \\
\hline & $(0.2 \pm 0.03)$ & $(3.5 \pm 1.31)$ & $(12.22 \pm 1.46)$ & & \\
\hline \multirow[t]{2}{*}{$5 b$} & $67.98 \pm 9.51$ & $161.03 \pm 19.36$ & $98.8 \pm 7.0$ & NI & NI \\
\hline & $(28.6 \pm 4.0)$ & $(67.7 \pm 8.14)$ & $(41.52 \pm 2.93)$ & & \\
\hline Reference & Aminogaunidine & Aminogaunidine & Indomethacin & NI & Diprotin-A (Ile-Pro-Ile) \\
\hline \multirow[t]{2}{*}{ Drug } & $3.1 \pm 0.35 \mu \mathrm{M}$ & $5394.4 \pm 1345.21 \mu \mathrm{M}$ & $212 \pm 8 \mu \mathrm{M}$ & & $5.14 \pm 0.75 \mu \mathrm{M}$ \\
\hline & $(0.34 \pm 0.0 \mu \mathrm{g} / \mathrm{mL})$ & $(596.62 \pm 148.8 \mu \mathrm{g} / \mathrm{mL})$ & $(75.9 \pm 4.7 \mu \mathrm{g} / \mathrm{mL})$ & & $(1.76 \pm 0.26 \mu \mathrm{g} / \mathrm{mL})$ \\
\hline
\end{tabular}

Results are mean $\pm \mathrm{SD}(\mathrm{n}=3-4$ independent replicates). IC50 values (concentration at which $50 \%$ inhibition of bioactivity determined in comparison to non-induced basal incubations) were calculated within dosage range $(\mu \mathrm{g} / \mathrm{mL})$. Bolded numerals stand out as the least $\mathrm{IC}_{50}$ values (most active) among others enlisted. NI, Non Inhibitory in the tested range of concentrations

5b). Impressively, 3a and 4a demonstrated activity lower than $10 \mu \mathrm{M}$. Appreciable antiproliferative effectiveness of tested compounds $3 a-5 a$ and $3 b-5 b$ against a panel of cancer cell lines was demonstrated with respective $\mathrm{IC}_{50}$ values (Table 2). Cisplatin antiproliferative efficacies in all colorectal carcinomas are further illustrated (the same Table). Noticeably among these present bioactive compounds; none could be identified for its outstanding antiprolifertaive capacities as compared to cisplatin in the whole panel colorectal cancer cell lines. Nevertheless, incomparable to cisplatin unselective cytoxicity in noncancerous periodontal ligament fibroblasts; tested compounds could be ascribed a high safety profile.

\section{Discussion}

\section{Chemistry}

The 1H NMR spectra of all of the synthesized compounds contained a doublet for $\mathrm{H}-5(\mathrm{JH}-\mathrm{F}=11-13 \mathrm{~Hz})$ at $\sim 8.0 \mathrm{ppm}$. The splitting of this signal was caused by the vicinal fluorine and indicated the presence of the FQ nucleus in all of these compounds. Similarly, the singlet
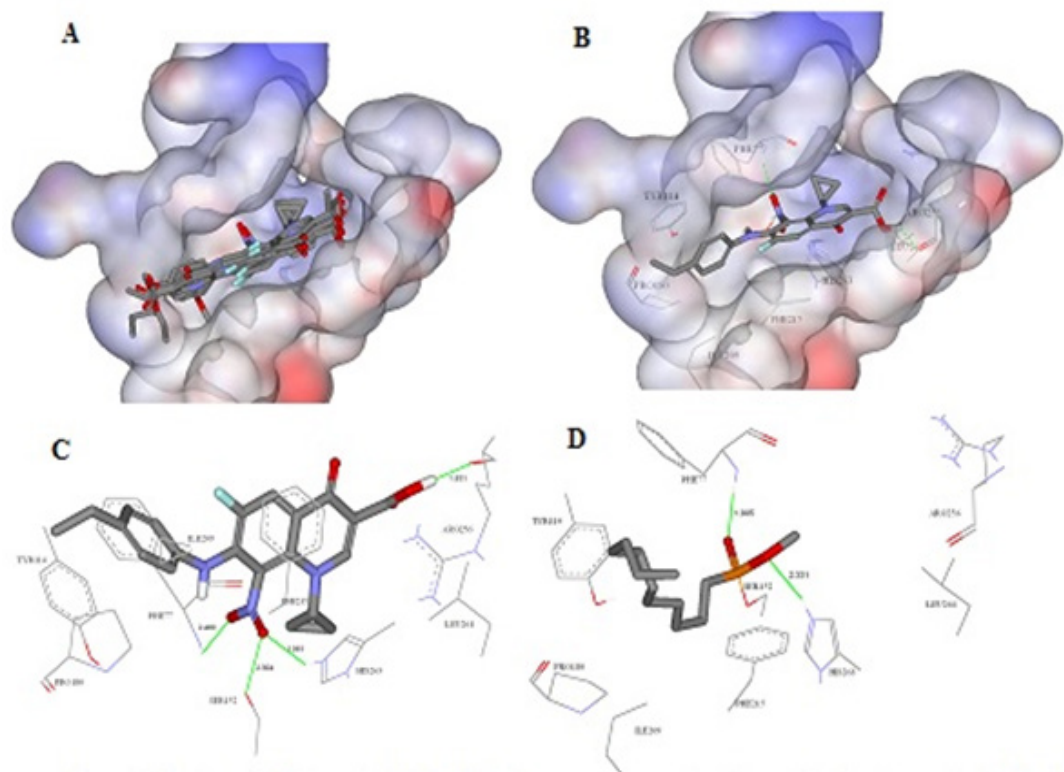

Figure 1. Docking Simulation Using FRED. A, Overlay image representing the predicted binding modes for the QDs within the solvent accessible surface area of the active site of pancreatic lipase enzyme (PDB code: 1LPB); B, The predicted binding mode of the most potent compound Q1(IC50 $=21.57 \pm 1.5 \mu \mathrm{M}) ; \mathrm{C}$, Detailed view of the docked pose of $3 \mathrm{a}$ and the corresponding interacting amino acids within the active site of PL;D, Co-crystallized ligand. 
Table 2. $\mathrm{IC}_{50}$ Values $(\mu \mathrm{M} ; \mu \mathrm{g} / \mathrm{mL})$ of In vitro Antiproliferative and Antilipolytic Activities of Tested Compounds and Reference Drugs on Colorectal Cancer Cell Lines and Pancreatic Triacylglycerol Lipase Bioassay

\begin{tabular}{|c|c|c|c|c|c|c|c|}
\hline \multirow[b]{2}{*}{ Treatment } & \multicolumn{6}{|c|}{ Cytotoxicity (as of \%Control) $\mathrm{IC}_{50}$ value $\mu \mathrm{M}(\mu \mathrm{g} / \mathrm{mL}$ ) } & \multirow{2}{*}{$\begin{array}{l}\text { PL-IC }{ }_{50} \text { value } \\
\mu \mathrm{M}(\mu \mathrm{g} / \mathrm{mL})\end{array}$} \\
\hline & HT29 & HCT116 & SW620 & $\mathrm{CACO} 2$ & SW480 & Fibroblasts & \\
\hline \multirow[t]{2}{*}{$3 \mathrm{a}$} & NI & $651.5 \pm 81.7$ & $686.5 \pm 85.7$ & $2011.6 \pm 137.5$ & $560.8 \pm 59.7$ & $437.2 \pm 25.2$ & $21.6 \pm 1.5$ \\
\hline & & $(268.01 \pm 33.6)$ & $(282.5 \pm 35.3)$ & $(827.6 \pm 56.6)$ & $(230.7 \pm 24.6)$ & $(179.9 \pm 10.4)$ & $(8.9 \pm 0.6)$ \\
\hline \multirow[t]{2}{*}{$4 a$} & $60.5 \pm 3.7$ & $39.1 \pm 0.4$ & $37.8 \pm 1.0$ & $67.0 \pm 9.7$ & $40.5 \pm 0.5$ & $37.1 \pm 0$. & $22.3 \pm 3.9$ \\
\hline & $(23.07 \pm 1.4)$ & $(14.9 \pm 0.2)$ & $(14.4 \pm 0.4)$ & $(25.6 \pm 3.7)$ & $(15.4 \pm 0.2)$ & $(14.2 \pm 0.13)$ & $(9.1 \pm 1.6)$ \\
\hline \multirow[t]{2}{*}{$5 \mathrm{a}$} & $207.0 \pm 7.6$ & $130.5 \pm 4.2$ & $83.8 \pm 4.4$ & $633.7 \pm 63.4$ & $148.8 \pm 6.1$ & $154.9 \pm 1.8$ & $95.5 \pm 5.9$ \\
\hline & $(81.2 \pm 2.97)$ & $(51.2 \pm 1.6)$ & $(32.9 \pm 1.75)$ & $(248.7 \pm 24.9)$ & $(58.4 \pm 2.71)$ & $(60.8 \pm 0.7)$ & $(37.5 \pm 2.3)$ \\
\hline \multirow[t]{2}{*}{$3 b$} & $1367.0 \pm 280.0$ & $573.2 \pm 84.2$ & $428.9 \pm 17.4$ & $136.1 \pm 16.7$ & $372.9 \pm 29.5$ & $416.2 \pm 14.3$ & $23.1 \pm 3.96$ \\
\hline & $(600.8 \pm 123.05)$ & $(251.9 \pm 37.01)$ & $(188.5 \pm 7.7)$ & $(59.8 \pm 7.4)$ & $(163.9 \pm 12.97)$ & $(182.9 \pm 6.3)$ & $(10.2 \pm 1.7)$ \\
\hline \multirow[t]{2}{*}{$4 b$} & $1532.4 \pm 30.5$ & $457.7 \pm 32.2$ & $617.3 \pm 46.4$ & $82.9 \pm 8.9$ & $448.3 \pm 35.0$ & $407.0 \pm 9.2$ & $74.7 \pm 3.7$ \\
\hline & $(627.5 \pm 12.5)$ & $(187.4 \pm 13.2)$ & $(252.8 \pm 19.0)$ & $(33.97 \pm 3.6)$ & $(183.6 \pm 14.3)$ & $(166.7 \pm 3.8)$ & $(28.5 \pm 1.4)$ \\
\hline \multirow[t]{2}{*}{$5 b$} & $43.8 \pm 0.8$ & $44.3 \pm 3.5$ & $40.0 \pm 5.0$ & $327.5 \pm 63.2$ & $45.8 \pm 1.8$ & $42.5 \pm 1.1$ & $88.6 \pm 5.5$ \\
\hline & $(18.4 \pm 0.4)$ & $(18.64 \pm 1.5)$ & $(16.8 \pm 2.1)$ & $(137.7 \pm 26.6)$ & $(19.3 \pm 0.8)$ & $(17.9 \pm 0.5)$ & $(37.3 \pm 2.3)$ \\
\hline Reference & Cisplatin & Cisplatin & Cisplatin & Cisplatin & Cisplatin & Cisplatin & Orlistat \\
\hline \multirow[t]{2}{*}{ Drug } & $2.1 \pm 0.2$ & $11.4 \pm 0.02$ & $1.7 \pm 0.3$ & $0.4 \pm 0.06$ & $1.6 \pm 0.2$ & $2.1 \pm 0.2$ & $0.2 \pm 0.0$ \\
\hline & $(6.9 \pm 0.5)$ & $(38.0 \pm 0.1)$ & $(5.7 \pm 0.9)$ & $(1.3 \pm 0.2)$ & $(5.3 \pm 0.7)$ & $(7.0 \pm 0.7)$ & $(0.11 \pm 0.01)$ \\
\hline
\end{tabular}

Results are mean \pm SD $\left(n=3-4\right.$ independent replicates). $\mathrm{IC}_{50}$ values (concentration at which $50 \%$ inhibition of cell proliferation took place in comparison to non-induced basal $72 \mathrm{~h}$ incubations) were calculated within $0.1-200 \mu \mathrm{g} / \mathrm{mL}$ range. NI: Non Inhibitory in the tested range of concentrations.

for H-2 at $~ 9.0$ ppm effectively confirmed that compound 1 had been formed successfully. Similar patterns were also observed for compounds $2 \mathrm{a}-5 \mathrm{a}$ and $2 \mathrm{~b}-5 \mathrm{~b}$ (H-5 in compounds $5 \mathrm{a}, 5 \mathrm{~b})$. The $1 \mathrm{H}$ NMR spectra of compounds $2 \mathrm{a}-5 \mathrm{a}$ and $2 \mathrm{~b}-5 \mathrm{~b}$ contain two new multilplets and broad singlets in the range of $0.85-2.4$, which were assigned to the aliphatic side chain. These signals effectively confirmed that ethylaniline and butylaniline had been effectively incorporated into compounds $2 \mathrm{a}-5 \mathrm{a}$ and 2b-5b. Moreover, new singlets, two new doublet of doublet and broad singlets in the ranges of 6.62-7.4 and 7.8-9.1 had appeared in the1H NMR spectra of compounds $2 \mathrm{a}-5 \mathrm{a}$ and $2 \mathrm{~b}-5 \mathrm{~b}$ which were assigned to the aromatic side chain and NH-aromatic, respectively. Again, these signals effectively confirmed that ethylaniline and butylaniline had been effectively incorporated into compounds $2 \mathrm{a}-5 \mathrm{a}$ and $2 \mathrm{~b}-5 \mathrm{~b}$. Furthermore, the appearance of a broad singlet at 4.2-4.5 ppm indicated that the reduction step had proceeded successfully to give compounds $4 \mathrm{a}$ and $4 \mathrm{~b}$. The disappearance of such broad singlet confirmed that compounds $4 \mathrm{a}$ and $4 \mathrm{~b}$ had undergone the diazotization and further cyclization reactions to give their cyclized respective $5 \mathrm{a}$ and $5 \mathrm{~b}$. All of the carbons belonging to the ethylaniline and butylaniline side chains were recognizable by their number, position and orientation in depth charts in the aliphatic and the aromatic regions. These signals confirmed that the ethylaniline and butylaniline side chains had been successfully incorporated. The 13C NMR spectra of compounds $1,2 \mathrm{a}-5 \mathrm{a}$ and $2 \mathrm{~b}-5 \mathrm{~b}$ contained a doublet ( $1 \mathrm{JC}-\mathrm{F}=250 \mathrm{~Hz}$ ) at $\sim 150 \mathrm{ppm}$ for C-6 (C-4 in compounds $5 \mathrm{a}$ and $5 \mathrm{~b}$ ), which indicated the presence of the FQ nucleus in all of these compounds. The splitting of the neighbouring carbon signals at C-5 (C-3a in compounds $5 \mathrm{a}$ and $5 \mathrm{~b}$ ) and $\mathrm{C}-7$ (C-5 in compounds $5 \mathrm{a}$ and $5 \mathrm{~b}$ ) into doublet peaks in these compounds (2JC-F $\sim 20 \mathrm{~Hz}$ ) effectively confirmed that they were all vicinal to a fluorine atom.

\section{DUAL glycation_inflammation inhibitory potential of} FQs and TFQs

Recently, the accumulation of advanced glycation end products (AGEs) in vivo has been implicated as a major pathogenic process in atherosclerosis, Alzheimer's disease and normal aging. Also, accelerated AGEs buildup under hyperglycemic conditions is a characteristic of type $2 \mathrm{DM}$ and contributes to the development of vascular complications. As such, inhibition of AGE formation represents a potential therapeutic target for the prevention of premature aging and treatment of diabetic complications. Methylglyoxal, a metabolite increased in diabetes, induces cell death through endoplasmic reticulum stress-associated ROS production and mitochondrial dysfunction (Chan et al., 2016). It is associated with insulin resistance, vascular dysfunction and neuropathies (Shamsaldeen et al., 2016). Naturally occurring polyphenols were confirmed for their physiologically regulated antiglycation action mechanisms (Valavala et al., 2011; Yeh et al., 2017). The antioxidative-antiinflammtory troxerutin (a flavonol derivative of rutin) was proven for its antiglycation potential in preventing the postglycation aggregation of albumin (Awasthi et al., 2017). Glycated albumin was found proinflammtory eliciting the activation and secretion of cytokines (Ibrahim et al., 2011). Besides Non-enzymatic glycosylation of human serum albumin manifests immunological complications in diabetes mellitus due to change in its structure that enhances neo- epitopes generation with high autoantibodies titre (Raghav et al., 2016; Raghav et al., 2017). Recently, anti-inflammatory molecules that inhibit AGEs have been shown to be good candidates for ameliorating diabetic 
complications as well as degenerative diseases (Byun et al., 2017). Scaffold similarities among the structures of polyphenols and FQs attracted our attention to investigate the inhibitory activities of the synthetic FQs and TFQs $3 a-5 a$ and $3 b-5 b$ as dual glycation-inflammation inhibitors. Our selection was based entirely on the simple postulation that similar chemical structures could have similar biological activities (Polur et al., 2011). Further work is still necessary to enhance its efficacies via optimizing their structure activity relationship (SAR).

\section{In vitro $D P P I V$ inhibition}

Intense efforts by pharmaceutical industry to identify new targets for obesity-diabetes (Diabesity) pharmacological intervention has led to a number of agents developed and directed at DPP IV [dipeptidyl peptidase IV] enzyme inhibition. Here, we place particular emphasis on two peptide substrates of DPP IV with insulin-releasing and antidiabetic actions namely, glucagon-like peptide-1 (GLP-1) and glucose-dependent insulinotropic polypeptide (GIP). The rationale for inhibiting DPP IV activity is decreasing peptide cleavage and thereby enhances endogenous incretin hormone activity thus reaping the anti-diabetes therapeutic benefits from reduced inactivation of GLP-1 and GIP by DPP IV inhibition. Significant unmet needs in diabetes therapy remain fuelling a notably large pipeline of DPPIV inhibitors and GLP-1 agonists market growth, driven by the obesity epidemic and improved diagnostic rates accompanied by large growth in patient numbers. Interestingly, DPP IV inhibitors from synthetic products have some advantages as in high stability in physiological conditions and a wide variety of chemical structures for the design of highly potent drugs.

\section{PL inhibitory- and In vitro antiproliferation activities}

At this stage, we can suggest that the antilipase activity refers mainly to 4-oxo-pyridine-3-carboxylic acid. Moreover, It is well known that highly lipophilic ligands e.g., orlistat with $\mathrm{C} \log \mathrm{P}>8$ have high inhibitory activity due to their lipophilic character that perfectly fit the lipophilic catalytic site of PL. The high activity of these compounds could be also attributed to the hydrogen bond network that they are capable to form through C-7 in compounds $4 \mathrm{a}, 3 \mathrm{~b}$ and $5 \mathrm{~b}, \mathrm{C}-8$ in compound $4 \mathrm{c}$ or $\mathrm{COOH}$ with lipolytic site of the enzyme, mainly Ser-152 residue (Figure 1). According to results shown in Table 2 , we have figured out that lipophilicity has an essential role in the antineoplastic activity against colorectal cancer cells. In addition, hydrogen bond networking is obvious and strong in the case of nitro acids ( $3 a$ and $3 b$ ) and the reduced acids ( $4 \mathrm{a}$ and $4 \mathrm{~b}$ ).

In conclusion, six newly synthesized FQs and TFQs were tested with respect to their in vitro dual glycation inflammation modulation, DPP IV inhibitory activity, antilipase and antiproliferative activities. Further structural modification and optimization is required to improve inhibitory activities of this novel series of FQs and TFQs. Action mechanistic studies for enzyme inhibition and apoptogenic antiproliferative efficacies need to be undertaken. The active compounds with proven dual antiglycation-antiinflammatory propensities correlate well with its proposed success at retarding and reversing development and progression of diabetic complications and aging, thus providing templates for drug design with high safety and efficacy profile. Novel antidiabesity strategies may be formulated thereby translating active compounds inclusion in healthy diet to the clinical practice for treatment/prevention of diabesity-related chronic diseases. Further assessment and treatment of the diabesity patients should address overall cardiovascular disease risk mainly attributable to adiposity; where closely monitored clinical trials can identify the most effective drug therapies for reducing cardiovascular disease in obese patients.

\section{Acknowledgements}

We are grateful for the Scientific Research Fund at the Ministry of Higher Education [SRF/MPH/1/05/2014] and the Deanship of Scientific Research and Quality Assurance at the University of Jordan [1850] for funding this work.

\section{Disclosure of interest}

The authors report no conflicts of interest.

\section{References}

Al-Hiari YM, Kasabri VN, Shakya AK, et al (2014) Fluoroquinolones: novel class of gastrointestinal dietary lipid digestion and absorption inhibitors. Med Chem Res, 23, 1-11.

Al-Hiari YM, Al-Mazari IS, Shakya AK, Darwish RM, Abu-Dahab R (2007). Synthesis and antibacterial properties of new 8- nitrofluoroquinolone derivatives. Molecules, 12 , 1240-58.

Almasri IM, Taha MO, Mohammad MK (2013). New leads for DPP IV inhibition: structure-based pharmacophore mapping and virtual screening study. Arch Pharm Res, 36, 1326-37.

Arabiyat S, Al-Rabi'ee A, Zalloum H, et al (2016). Antilipolytic and hypotriglyceridemic effects of dietary Salvia triloba Lf (Lamiaceae) in experimental rats. Trop J Pharm Res, 15, 723-8.

Argirova M, Argirov O (2003). Inhibition of ascorbic acid-induced modifications in lens proteins by peptides. J Peptide Sci, 9, 170-6.

Assanga SBI, Luj LML, Gil-Salido AA, et al (2017). Anti-inflammatory activity and modulate oxidative stress of Bucida buceras in lipopolysaccharide-stimulated RAW 264.7 macrophages and Carrageenan-induced acute paw edema in rats. $J$ Med Plants Res, 11, 239-52.

Appelbaum PC, Hunter PA (2000). The fluoroquinolone antibacterials: past, present and future perspectives. Int $J$ Antimicr Agent, 16, 5-15.

Asif M (2014). A brief review on antitubercular activity of pharmacological active some Triazole Analogues. Glob $J$ Res Rev, 1, 51-8.

Asif M (2015). Anti-neuropathic and anticonvulsant activities of various substituted triazoles analogues. Chem Int, 1, 174-83.

Awasthi S, Ravi A, Saraswathi NT (2017). Troxerutin imparts preservative effects on albumin by preventing Maillard reaction- mediated early and advanced glycation modification. J Biomol Struct Dyn, 35, 2681-7.

Ball P (2000). Quinolone generations: natural history or natural selection?. J Antimicrob Chemother, 46, 17-24.

Bentley D, Young A-M, Rowell L, et al (2012). Evidence of a drug-drug interaction linked to inhibition of ester hydrolysis by orlistat. J Cardiovasc Pharm, 60, 390-6. 
Bolon MK (2011). The newer fluoroquinolones. Medi Clin North $A m$, 95, 793-817.

Byun K, Yoo Y, Son M, et al (2017). Advanced glycation endproducts produced systemically and by macrophages: A common contributor to inflammation and degenerative diseases. Pharm Therap, 177, 44- 55

Carta A, Piras S, Palomba M, et al (2008). Anti-mycobacterial activity of quinolones. Triazoloquinolones a new class of potent anti-mycobacterial agents. Anti-Infect Agents Med Chem, 7, 134-47.

Chakrabarti R, Bhavtaran S, Narendra P, et al (2011). Dipeptidyl peptidase-IV inhibitory activity of Berberis aristata. $J$ Nat Prod, 4, 158-63.

Chan C-M, Huang D-Y, Huang Y-P, et al (2016). Methylglyoxal induces cell death through endoplasmic reticulum stress-associated ROS production and mitochondrial dysfunction. J Cell Mol Med, 20, 1749-60.

Coughlan MT, Yap FYT, Tong DCK, et al (2011). Advanced glycation end products are direct modulators of $\beta$-cell function. Diabetes, 60, 2523-32.

di Wu Q, Wang JH, Fennessy F, Redmond HP, Bouchier-Hayes D (1999). Taurine prevents high-glucose-induced human vascular endothelial cell apoptosis. Am J Cell Physiol, 277, 1229-38.

Edmont DS, Rocher R, Plisson C, Chenault J (2000). Synthesis and evaluation of quinoline carboxyguanidines as antidiabetic agents. Bioorg Med Chem Lett, 10, 1831-4.

El-Rayes BF, Grignon R, Aslam N, Aranha O, Sarkar FH (2002). Ciprofloxacin inhibits cell growth and synergizes the effect of etoposide in hormone resistant prostate cancer cells. Int J Oncol, 21, 207-11.

Farsalinos KE, Romagna G, Tsiapras D, Kyrzopoulos S, Voudris V (2013). Evaluating nicotine levels selection and patterns of electronic cigarette use in a group of "vapers" who had achieved complete substitution of smoking. Subst Abuse Res Treat, 7, 139-46.

Ghimeray AK, Lee HY, Kim YH, Ryu EK, Chang MS (2015). Evaluation of antioxidant and anti-inflammatory effect of Rhododendron brachycarpum extract used in skin care product by in vitro and in vivo test. Tech Inv, 6, 105.

Gómez-Peralta F, Abreu C, Mora-Navarro G, et al (2011). Switching from premixed insulin to basal Insulin analogue for type 2 diabetes and role of Dipeptidyl Peptidase-4 Inhibitors. Exp Clin Endocrin Diabetes, 92, 1-10.

Gorrell MD (2005). Dipeptidyl peptidase IV and related enzymes in cell biology and liver disorders. Clin Sci, 108, 277-92.

Guedes S, Vitorino R, Domingues MRM, Amado F, Domingues P (2009). Mass spectrometry characterization of the glycation sites of bovine insulin by tandem mass spectrometry. $J \mathrm{Am}$ Soc Mass Spectr, 20, 1319-26.

Habtemariam S (2012). The anti-obesity potential of sigmoidin A. Pharm Biol, 50, 1519-22.

Haider S, Alam MS, Hamid H (2014). 1, 2, 3-triazoles: Scaffold with medicinal significance. Inflam Cell Signal, 1, 95-105.

Harris CS, Beaulieu L-P, Fraser M-Hl, et al (2011). Inhibition of advanced glycation end product formation by medicinal plant extracts correlates with phenolic metabolites and antioxidant activity. Planta Med, 77, 196-204.

Horie A, Tokuyama Y, Ishizuka T, et al (2014). The dipeptidyl peptidase-4 inhibitor vildagliptin has the capacity to repair $\beta$-cell dysfunction and insulin resistance. Horm Metab Res, 46, 814-8.

Hsu K-C, Tung Y-S, Huang S-L, Jao C-L (2013). Dipeptidyl peptidase-IV inhibitory activity of peptides in porcine skin gelatin hydrolysates. Bioactive food peptides in health and disease: InTechOpen, Chapter 8, pp 205-18.

Huang J, Wang Y, Li C, Wang X, He X (2016).
Anti-Inflammatory Oleanolic Triterpenes from Chinese Acorns. Molecules, 21, 669-77.

Hunter SJ, Boyd AC, O'Harte FPM, et al (2003). Demonstration of glycated insulin in human diabetic plasma and decreased biological activity assessed by euglycemic-hyperinsulinemic clamp technique in humans. Diabetes, 52, 492-8.

Ibrahim AS, El-Remessy AB, Matragoon S, et al (2011). Retinal microglial activation and inflammation induced by amadori-glycated albumin in a rat model of diabetes. Diabetes, 60, 1122-33.

Jao C-L, Hung C-C, Tung Y-S, et al (2015). The development of bioactive peptides from dietary proteins as a dipeptidyl peptidase IV inhibitor for the management of type 2 diabetes. Biomed, 5, 9-15.

Kasabri V, Afifi FU, Abu-Dahab R, et al (2014). In vitro modulation of metabolic syndrome enzymes and proliferation of obesity related-colorectal cancer cell line panel by Salvia species from Jordan. Rev Roum Chim, 59, 693-705.

Kathiravan MK, Khilare MM, Nikoomanesh K, Chothe AS, Jain KS (2013). Topoisomerase as target for antibacterial and anticancer drug discovery. J Enz Inh Med Chem, 28, 419-35.

Kawalec P, Mikrut A, Łopuch S (2014). The safety of dipeptidyl peptidase-4 (DPP-4) inhibitors or sodium-glucose cotransporter 2 (SGLT-2) inhibitors added to metformin background therapy in patients with type 2 diabetes mellitus: a systematic review and meta-analysis. Diabetes Met Syndr Res Rev, 30, 269-83.

Keita Y, Michailova M, Kratzer W, et al (1992). Influence of penicillamine on the formation of early non-enzymatic glycation products of human serum proteins. Int J Clin Pharmcol, 30, 441-2.

Langer O, Mitterhauser M, Wadsak W, et al (2003). A general method for the fluorine-18 labelling of fluoroquinolone antibiotics. J Labell Comp Radiopharm, 46, 715-27.

McKillop AM, McCluskey JT, Boyd AC, et al (2000). Production and characterization of specific antibodies for evaluation of glycated insulin in plasma and biological tissues. $J$ Endocrinol, 167, 153-63.

O'Harte FPM, Højrup P, Barnett CR, Flatt PR (1996). Identification of the site of glycation of human insulin. Peptides, 17, 1323- 30.

O'Harte FPM, Boyd AC, McKillop AM, et al (2000). Structure, antihyperglycemic activity and cellular actions of a novel diglycated human insulin. Peptides, 21, 1519-26.

OEDOCKING 3.2.0.2: OpenEye Scientific Software, Santa Fe, NM. (http://www.eyesopen.com), (2015).

Peng X, Ma J, Chen F, Wang M (2011). Naturally occurring inhibitors against the formation of advanced glycation end-products. Food Funct, 2, 289-301.

Polur H, Joshi T, Workman CT, Lavekar G, Kouskoumvekaki I (2011). Back to the roots: prediction of biologically active natural products from Ayurveda traditional medicine. $\mathrm{Mol}$ Inf, 30, $181-7$.

Puddu AL, Viviani G (2011). Advanced glycation endproducts and diabetes. Beyond vascular complications. Endocr Metab Immun Disord Drug Targets, 11, 132-40.

Raghav A, Ahmad J, Alam K (2016). Impact of glycation on structural and antioxidant function of human serum albumin: relevance in diabetic complications. Diabetes Metab Syndr Clin Res Rev, 10, 96-101.

Raghav A, Ahmad J, Alam K (2017). Nonenzymatic glycosylation of human serum albumin and its effect on antibodies profile in patients with diabetes mellitus. PLoS One, 12, e0176970.

Ramamurthy B, Jones AD, Larsson L (2003). Glutathione reverses early effects of glycation on myosin function. $\mathrm{Am}$ J Cell Phys, 285, 419-24.

Saleh S, Mohammad M, Mashallah SH, et al (2012). Inhibition of 
DPP IV is a suggested mechanism of the immunomodulatory effects of sparfloxacin. Sci Res Essent, 7, 310-7.

Savarese G, D'Amore C, Federici M, et al (2016). Effects of dipeptidyl peptidase 4 inhibitors and sodium-glucose linked cotransporter-2 inhibitors on cardiovascular events in patients with type 2 diabetes mellitus: a meta-analysis. Int J Cardiol, 220, 595-601.

Shaharyar M, Ali MA, Abdullah MM (2007). Synthesis and antiproliferative activity of 1-[(sub)]-6-fluoro-3-[(sub)]-1,3, 4-oxadiazol-2- yl-7-piperazino-1, 4-dihydro-4-quinolinone derivatives. Med Chem Res, 16, 292-9.

Shamsaldeen AYS, Mackenzie LA, Lione LD, Benham C (2016). Methylglyoxal, a metabolite increased in diabetes is associated with insulin resistance, vascular dysfunction and neuropathies. Curr Drug Metab, 17, 359-67.

Shu T, Zhu Y, Wang H, et al (2011). AGEs decrease insulin synthesis in pancreatic $\beta$-cell by repressing Pdx-1 protein expression at the post-translational level. PLoS One, 6, e18782.

Singh A-K, Jatwa R, Purohit A, Ram H (2017). Synthetic and phytocompounds based dipeptidyl peptidase-IV (DPP-IV) inhibitors for therapeutics of diabetes. J Asian Nat Prod Res, 19, 1036-45.

Sissi C, Palumbo M (2003). The quinolone family: from antibacterial to anticancer agents. Curr Med Chem, 3, 439-50.

Szwergold BS (2005). Intrinsic toxicity of glucose, due to nonenzymatic glycation, is controlled in-vivo by deglycation systems including: FN3K-mediated deglycation of fructosamines and transglycation of aldosamines. Med Hypoth, 65, 337-48.

Szwergold BS, Howell SK, Beisswenger PJ (2005a). Transglycation-A potential new mechanism for deglycation of Schiff's bases. Ann NY Acad Sci U S A, 1043, 845-64.

Szwergold BS (2005b). Carnosine and anserine act as effective transglycating agents in decomposition of aldose-derived Schiff bases. Biochem Biophys Res Comm, 336, 36-41.

Szwergold BS (2006). Alpha-Thiolamines such as cysteine and cysteamine act as effective transglycating agents due to formation of irreversible thiazolidine derivatives. Med Hypoth, 66, 698-707.

Vanhoof G, De Meester I, Van Sande M, Scharpe S, Yaron A (1992). Distribution of proline-specific aminopeptidases in human tissues and body fluids. Clin Chem Lab Med, 30, 333-8.

Valavala VK, Vangipurapu RK, Banam VR, et al (2011). Effect of mustard (Brassica juncea) leaf extract on streptozotocin induced diabetic cataract in Wister rats. $J$ Food Biochem, 35, 109-24.

Vichai V, Kirtikara K (2006). Sulforhodamine B colorimetric assay for cytotoxicity screening. Nature Protoc, 1, 1112-6.

Wondrak GT, Cervantes-Laurean D, Roberts MJ, et al (2002). Identification of $\alpha$ - dicarbonyl scavengers for cellular protection against carbonyl stress. Biochem Pharm, 63, 361-73.

Wu C-H, Huang S-M, Lin J-A, Yen G-C (2011a). Inhibition of advanced glycation endproduct formation by foodstuffs. Food Funct, 2, 224-34.

Wu C-H, Huang H-W, Huang S-M, et al (2011b). AGE-induced interference of glucose uptake and transport as a possible cause of insulin resistance in adipocytes. J Agric Food Chem, 59, 7978-84.

Yeh W-J, Hsia S-M, Lee W-H, Wu C-H (2017). Polyphenols with antiglycation activity and mechanisms of action: A review of recent findings. J Food Drug Anal, 25, 84-92.

Zhao Y-L, Chen Y-L, Sheu J-Y,et al (2005). Synthesis and antimycobacterial evaluation of certain fluoroquinolone derivatives. Bioorg Med Chem, 13, 3921-6.

Zhang Y, Chen R, Ma H, Chen S (2015). Isolation and identification of dipeptidyl peptidase IV-inhibitory peptides from trypsin/chymotrypsin-treated goat milk casein hydrolysates by 2D-TLC and LC-MS/MS. J Agric Food Chem, 63, 8819-28.

Zhu Y, Shu T, Lin Y, et al (2011). Inhibition of the receptor for advanced glycation end products (RAGE) protects pancreatic-cells. Biochem Biophys Res Comm, 404, 159-65.

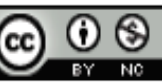

This work is licensed under a Creative Commons AttributionNon Commercial 4.0 International License. 